\title{
Anxiolytic-Like Action of Neuropeptide Y: Mediation by Y1 Receptors in Amygdala, and Dissociation from Food Intake Effects
}

Markus Heilig, M.D., Ph.D, Sarah McLeod, Michelle Brot, Ph.D., Steven C. Heinrichs, Ph.D., Fraderique Menzaghi, Ph.D., George F. Koob, Ph.D., and Karen T. Britton, M.D., Ph.D.

Bidence from animal and human studies suggests that mopeptide $Y(N P Y)$ may be a potent endogenous ciolytic. The anatomic structures mediating this action the peptide remain unknown. Furthermore, in addition its anxiolytic-like effects, intracerebroventricular ministration of NPY induces food intake through Spothalamic mechanisms, making the anxiolytic-like ction of the peptide more difficult to interpret. The mpose of this study was to examine the anatomic tsrate for the effects of NPY on anxiety, and to drecterize the NPY receptors mediating these effects. urcerebroventricular injection of NPY produced corsed food intake in free-feeding animals, and dosemandent anticonflict/anxiolytic-like effects in an unlished animal model of anxiety, the Geller-Seifter punished responding test. In contrast, microinjection of NPY into the central nucleus of the amygdala did not increase food intake in free-feeding animals, did not affect unpunished lever pressing for food, but did reproduce the anticonflict/anxiolytic-like effect with high potency. The selective NPY-Y1 agonist, $p\left[\mathrm{Leu}^{31}, \mathrm{Pro}^{34}\right] \mathrm{NPY}$ was approximately equipotent with native NPY in the conflict paradigm, and markedly more potent than the $Y 2$ agonist, NPY 13-36. Intrastriatal injections had no effect on conflict behavior. Thus, activation of $Y 1$ receptors in the central nucleus of the amygdala produces effects similar to established anxiolytics without affecting food intake, suggesting that Y1-receptors in the amygdala may be a substrate for anxiolytic actions of NPY.

[Neuropsychopharmacology 8:357-363, 1993]
Tr wORDs: Neuropeptide Y; Receptors; Amygdala; Sinss; Anxiety; Depression

Nowropeptide Y (NPY) (Tatemoto et al. 1982) is one of the most abundant peptide transmitters in the mamclian brain. In addition to numerous effects on endoaine and autonomic function, it produces striking berioral effects after central administration. Among tere, stimulation of food intake, and an anticonflict/

hom the Department of Neuropharmacology, The Scripps Research inte, (MH, MB, SH, FM, GFK), La Jolla, California; and the Diptment of Psychiatry, San Diego Veterans' Administration Mal Center, and University of California at San Diego (SM, KTB), upla, California.

Adtress correspondence to: Markus Heilig, M.D., Ph.D., Departof Psychiatry and Neurochemistry, University of Göteborg adals Sjukhus, S-431 80 Mölndal, Sweden.

Received July 7, 1992; revised November 24, 1992; accepted nuenber 1, 1992. anxiolytic-like action are prominent (for review see Heilig and Widerlöv 1990). The latter action of the peptide is particularly interesting in conjunction with reports that NPY may be involved in the pathophysiology of depressive and/or anxiety symptoms in humans (Widerlöv et al. 1988; Heilig and Widerlöv 1990; Widdowson et al. 1992).

The anviolytic-like action of NPY has been observed in different animal models of anxiety, but has only been reported after intracerebroventricular (ICV) administration of the peptide (Heilig et al. 1989). Therefore, the anatomic structures mediating this action of NPY remain unknown. Furthermore, ICV administration of NPY is sufficient to increase food intake (Clark et al. 1984). Therefore, an increased appetitive drive could constitute a confounding factor when apparent anxiolytic-like effects of NPY are observed after ICV adminis- 
tration, in particular in tests that rely on measures of consummatory behaviors.

It has been established that hypothalamic structures mediate the effects of NPY on food intake (Stanley and Leibovitz 1985; Levine and Morley 1984). Conversely, the amygdaloid complex and in particular the central nucleus of the amygdala are known to be important for emotionality, and the central nucleus receives a dense NPY-ergic innervation(Chronwall et al. 1985; ZardettoSmith and Gray 1990). The present study was undertaken to examine the question of whether orexigenic and anxiolytic-like effects of NPY can be anatomically dissociated, and to test the hypothesis that anxiolyticlike effects of NPY are produced in the amygdaloid complex. An established animal model of anxiety, the Geller-Seifter punished responding test (Pollard and Howard 1979) was used to assess anticonflict/anxiolyticlike effects. Food intake as well as conflict behavior were studied both after ICV injection of NPY and after microinjections into the central amygdaloid nucleus. Since a heterogeneity of central NPY receptors has been demonstrated (Wahlestedt et al. 1990; Aicher et al. 1991), selective ligands for NPY-Y1 and Y2 receptors were used to characterize the receptors involved in producing anxiolytic-like effects of NPY.

\section{MATERIALS AND METHODS}

\section{Subjects}

Male albino Wistar rats, weighing between 200 and $275 \mathrm{~g}$ at the start of the experiment were used. Animals were housed three per cage, in a light- and temperaturecontrolled environment. For operant training and testing, rats were food deprived to $85 \%$ of their free-feeding weight, and then maintained on $15 \mathrm{~g}$ food per day in addition to that earned during testing. The following groups of animals were used: ICV injections of NPYI conflict testing ( $n=32$, also used for the tail-flick test; these data have been published as a part of another study [Heilig et al. 1992]); amygdala injections of NPY and analogs/conflict testing $(n=30$; these animals were used in three separate experimental trials; they were allowed at least 7 treatment-free days aftereach of these, and were rerandomized for each trial); striatum injections of NPY/conflict testing $(n=15)$; ICV injections of NPY/food intake $(n=16)$; and amygdala injections of NPY/food intake $(n=16)$. All experimental procedures were approved by the animal ethics committee at the San Diego VA Medical Center.

\section{Surgical Procedure and Injections}

Under halothane anesthesia, animals were stereotactically implanted with guide cannulas, which were se- cured to the skull using stainless-steel screws and acrylix cement, and were closed with obturators when not used. At least 10 days of recovery were allowed after surgery. For ICV experiments, 23-gauge guide cannulas aimed $1 \mathrm{~mm}$ dorsal to a planned injection site in the lateral cerebral ventricle were used (final coordinates: $0.6 \mathrm{~mm}$ posterior and $2.0 \mathrm{~mm}$ lateral to bregma, $4.2 \mathrm{~mm}$ ventral to skull surface; tooth bar at $+5.0 \mathrm{~mm}$ ); pep tide or vehicle was injected over 1 minute through a 30-gauge injector connected to a Hamilton syringe in a volume of $5 \mu$ l. Conflict testing was started 60 minutes following injection. For amygdala injections, bilateral 26-gauge guides aimed $3.0 \mathrm{~mm}$ dorsal to the final injec. tion site were used $(2.3 \mathrm{~mm}$ posterior and $4.2 \mathrm{~mm}$ lateral to bregma, 8.1 ventral to skull surface; tooth bar at -3.3 $\mathrm{mm})$, and injections were given over 3 minutes through a 33-gauge injector in a volume of $0.5 \mu \mathrm{l}$. Conflict testing was performed 15 minutes after injection of drug. For intrastriatal injections, the same procedure was used as for the amygdala experiments, but the final coor. dinates were $1.0 \mathrm{~mm}$ anterior and $3.0 \mathrm{~mm}$ lateral to bregma, $5.0 \mathrm{~mm}$ ventral to skull surface; tooth bar at $-3.3 \mathrm{~mm}$. For the site injections, injectors were inserted and left in place for 3 minutes 2 days prior to the first actual injection to minimize nonspecific injection artifacts upon subsequent injections. For ICV injections, correct placement was ensured by gravity injection of $5 \mu \mathrm{l}$ saline prior to experiments. For site injections, coor dinates were histologically verified.

\section{Conflict Test}

Training and testing of animals was performed in sound-attenuated operantchambers (Coulbourn Instroments, Inc., Lehigh Valley, PA). Chambers were equipped with stainless-steel bar floors through which electric shock could be delivered. Animals were tint trained to lever-press for $45 \mathrm{mg}$ of Noyes food pellets on a continuous reinforcement schedule. They were subsequently switched to a random-interval 30-second reinforcement schedule, and finally trained on a multiple-schedule conflict test with incremental shod (Pollard and Howard 1979). The conflict test consisted of three components: a pure reward (unpunished) com ponent, a time-out component, and a conflict (purished) component. Responses made during the reward component were reinforced on a random-interval 30second schedule in a darkened chamber. The chamber was illuminated with a house light during the time-out component, and responses were not reinforced. The third component (conflict) was signaled by threeflastr ing lights above the lever $(1 / \mathrm{sec})$ and responses were both rewarded with food and punished with footshods on a continuous reinforcement schedule. Footshod consisted of a scrambled biphasic square-wave pro- 
duced by a SGS-003 stimulator (BRS/LVE Division of Techical Services Inc., Laurel, MD). During the conflict momponent, shock was incremental in $0.15-\mathrm{mA}$ steps ba maximum of $3.3 \mathrm{~mA}$ with delivery of every reinfreer.

A testing session consisted of a 5-minute reward priod, a 2-minute time-out, and a 2-minute conflict priod presented in succession, with this sequence peated twice. Testing sessions were repeated on sucassive days, at the same time of day. For each animal, weline responding during both unpunished and puntred components of the test was determined over two b three sessions preceding the session during which tug effects were studied. For each subject, respondin during the actual testing session (number of lever preses) was expressed as a percentage of this individur's baseline.

\section{lood Intake Experiments}

hseparate experiments, food intake was also measured in animals that had not undergone training for the melict test. Free-feeding rats were placed one per cage, ad habituated over 3 days to the introduction of a tinless-steel bowl containing a preweighed amount dNoyes precision pellets identical to those used in the molict test. On the experimental day, sawdust was removed, the bowl was introduced, and remaining food (xduding spill) was weighed after 30 minutes, 1 hour, and 2 hours.

\section{Tiif-Flick Test}

Atail-fick test was performed immediately following thesession during which effects of ICV NPY on conflict Shavior had been studied. In this test, rats were held, and the tail was dipped $3.5 \mathrm{~cm}$ in $55^{\circ} \mathrm{C}$ water. The bency for the tail to flick was measured (Jansen, 1963).

\section{tistical Analysis}

Pood Intake. The consumed amount of food at 30, 60, an 120 minutes was subjected to a two-way analysis dvariance with respect to treatment, time, and the iniration between these two.

Confict Test. The percent change of unpunished and puished responding versus pretrial baseline were reprately subjected to one-way analysis of variance with respect to treatment. Multiple comparisons versus untrols were performed using Dunnett's test.

\section{Anmicals}

turine NPY, p[ $\left[\mathrm{Leu}^{31}, \mathrm{Pro}^{34}\right] \mathrm{NPY}$ and NPY $13-36$ were all dained from Bachem California (Torrance, CA).

\section{RESULTS}

\section{Effects of Intracerebroventricular NPY}

Conflict Behavior. In the conflict experiment, average baseline responding on the unpunished component was $213.4 \pm 11.2$ lever presses per session, and on the punished component $19.3 \pm 0.8$ lever presses per session (mean \pm SEM). Neuropeptide $Y(0.2$ to $5.0 \mathrm{nmol})$ increased punished responding in a dose-dependent manner $(F[26,3]=9.0, p<.001)$. At the highest dose, punished responding was doubled ( $p<.001 \mathrm{vs.} \mathrm{con-}$ trols). A smaller increase in unpunished responding was also seen $(F[26,3]=4.2, p<.015)$, but was at most about $30 \%$, and had already reached a plateau at 1.0 nmol (Fig. 1).

Very similar results were observed in a replication of this experiment in a separategroup of rats. The doses of $0.2,1.0$ and $5.0 \mathrm{nmol}$ of NPY (i.c.v.) produced a dose dependent increase in punished responding reaching a maximum of $161 \%$ of control, with no significant effect on unpunished responding.

Food Intake. NPY $(2.0 \mathrm{nmol})$ produced a robust increase in food intake over 2 hours $(F[42,2,2,1]=20.1$,

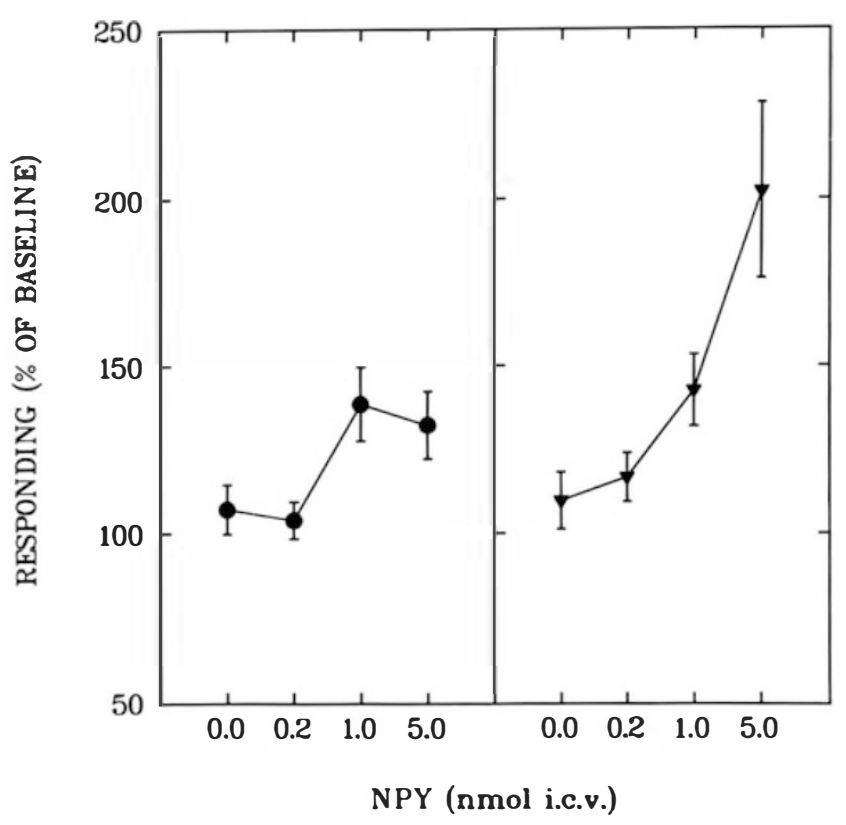

Figure 1. Dose-dependent increase of punished responding by NPY ( 0.2 to $5.0 \mathrm{nmol} \mathrm{ICV})$ in the Geller-Seifter conflict test. Unpunished responding was only marginally affected. Responding, that is, the number of lever presses during the 2-minute punished, or the 5-minute unpunished test component, respectively, is expressed as the percentage of a baseline value obtained over two to three sessions preceding the session in which injections were made. Values are means of six to eight animals \pm SEM. For statistical analysis, see the Results. ( $\bullet$, unpunished; $\nabla$, punished.) Reprinted with permission from Heilig et al. 1992. 


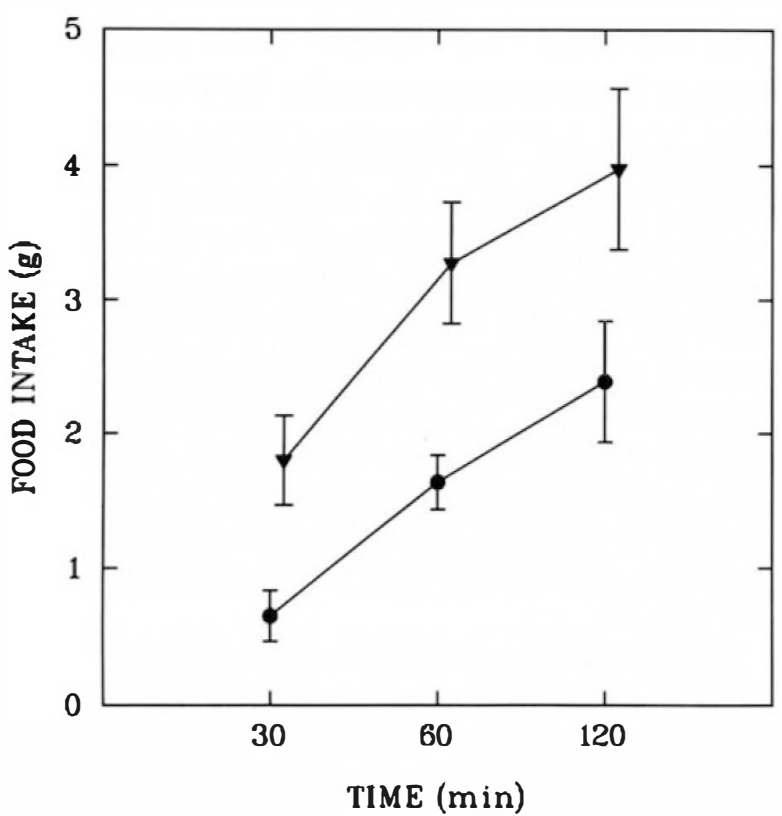

Figure 2. Increased food intake after ICV injection of NPY $(2.0 \mathrm{nmol})$ in free-feeding animals. Cumulative food intake during 2 hours is shown (mean $\pm \mathrm{SEM}, n=8$ ). For statistical analysis, see the Results. $(\bullet$, vehicle; $\nabla, N P Y$.)

$p<.001)$. There was no significant interaction between treatment and time (Fig. 2).

Pain Threshold. In the tail-flick experiment that followed administration of NPY to determine possible effects on pain threshold, no difference in latency to tail flick was seen, indicating that the increase in punished responding was not due to the analgesic effects of $\operatorname{NPY}(2.5 \pm 0.7,1.7 \pm 0.2$, and $1.7 \pm 0.1$ second; mean \pm SEM for $\mathrm{NaCl}$, and $0.2,1.0$, and $5.0 \mathrm{nmol} \mathrm{NPY}$, respectively; $(F[26,3]=.77, p<.52$, not significant).

\section{Effects of NPY and Its Analogs in the Central Nucleus of the Amygdala}

Food Intake. Free-feeding animals injected with NPY (100 pmol/side) in the central amygdaloid nucleus did not differ from vehicle-treated controls $(F[42,2,2,1]=$ $1.1, p=.32$, not significant; Fig. 3).

Conflict Behavior After NPYMicroinjection. Average baseline responding on the unpunished component was $359.6 \pm 34.6$ lever presses per session, and on the punished component $24.8 \pm 0.8$ lever presses per session (mean \pm SEM). NPY markedly increased punished responding both at the 50 and the $100 \mathrm{pmol} /$ side dose $(F[25,2]=7.7, p=.002$ for overall treatment effect; both groups differed from controls at $p<.01$ on Dunnett's test). Both doses were equally efficacious, indicating an $\mathrm{ED}_{50}$ below $50 \mathrm{pmol} / \mathrm{side}$. Unpunished responding was not affected (Fig. 4).

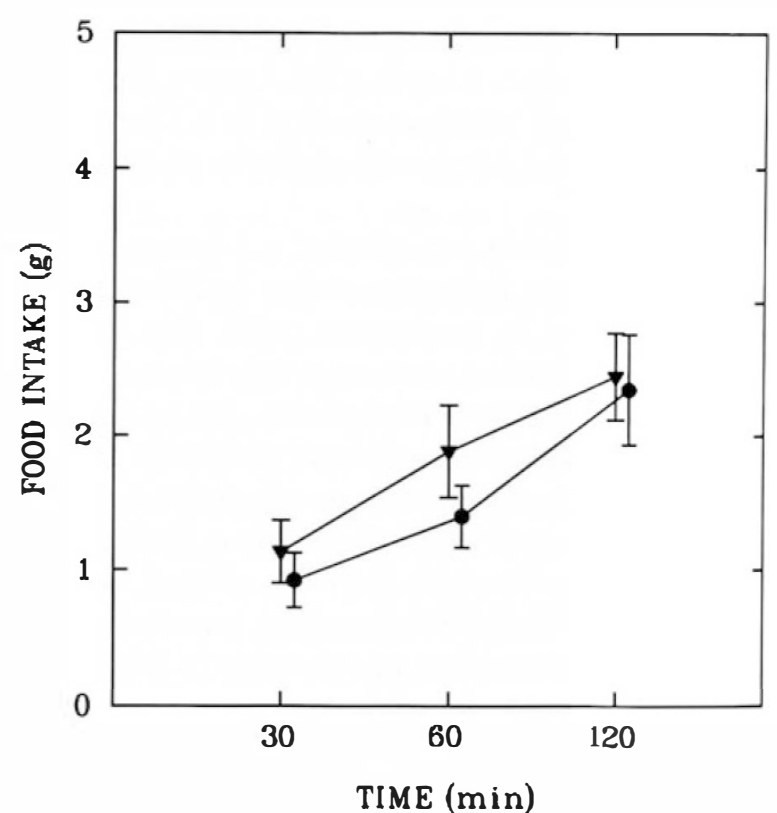

Figure 3. Lack of effect on food intake of NPY (100 pmol) injected into the central amygdaloid nucleus. Cumulative food intake during 2 hours is shown (mean \pm SEM, $n=8$ ). Test.

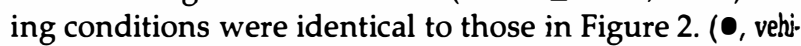
cle; $\boldsymbol{\nabla}$, NPY.)

Conflict Behavior After Microinjections of the Selective NPY-Y1 Receptor Agonist p[Leu ${ }^{31}$, Pro $\left.^{34}\right] N P Y$. Aver. age baseline responding on the unpunished component was $307.3 \pm 32.5$, and on the punished component 22.5 \pm 1.6 lever presses per session (mean \pm SEM). The Y1 agonist produced an increase of punished responding of à magnitude similar to that seen with native NPY at both 50 and $100 \mathrm{pmol} / \mathrm{side}(F[21,2]=6.7, p=.006$ for overall treatment effect; both groups differed from vehicle-injected controls at $p<.01$ on Dunnett's test). Also here, both doses were equally efficacious, indicating an $\mathrm{ED}_{50}$ below $50 \mathrm{pmol} / \mathrm{side}$. Unpunished responding was not affected (Fig. 5).

Conflict Behavior After Microinjection of the Selective NPY-Y2 Agonist NPY 13-36. Average baseline responding on the unpunished component was $319.6 \pm 43.6$, and on the punished component $25.75 \pm 1.8$ lever presses per session (mean \pm SEM). The $Y 2$ agonist was markedly less potent than NPY in producing a release of punished responding, requiring a dose of 200 $\mathrm{pmol} /$ side for a significant effect $(F[23,2]=4.0, p=.033$ for the overall treatment effect; the $100 \mathrm{pmol} / \mathrm{side}$ group not significantly different from controls, the $200 \mathrm{pmol}$ side different at $p=.037$ on Dunnett's test). The unpunished component was not affected (Fig. 6).

\section{Effects of Intrastriatal Microinjection of NPY}

Average baseline responding was $492.9 \pm 30.7$ on the unpunished, and $17.9 \pm 1.5$ on the punished compo- 


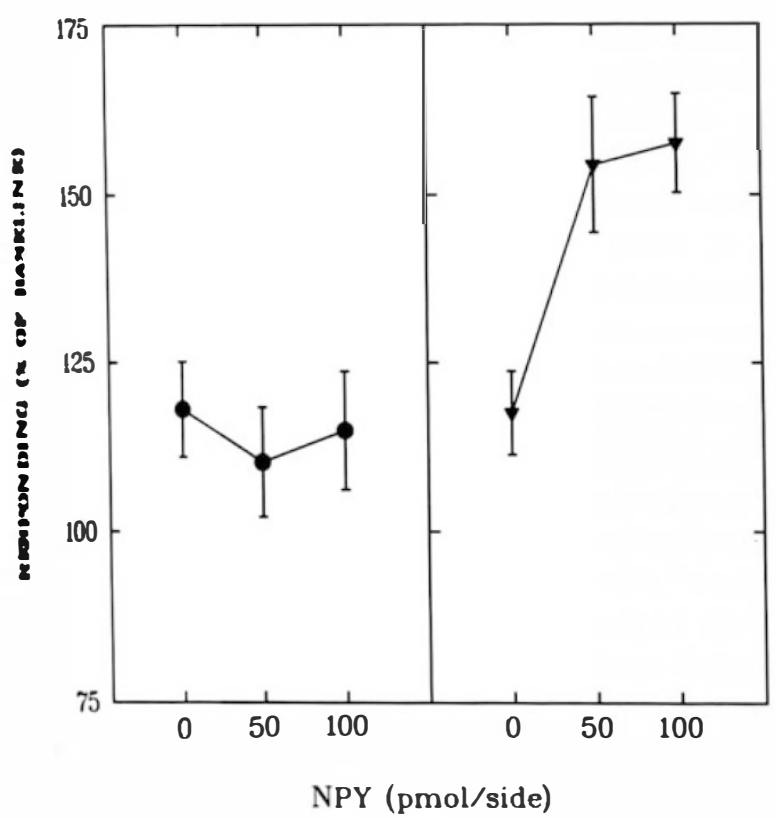

Fore 4. Markedly increased punished (right panel), and onfected unpunished (left panel) responding in the c.ler-Seifter conflict test after injection of NPY (50 to 100 pol side) into the central nucleus of the amygdala. Respondof is expressed as described in legend to Figure 1. Values means of 8 to 10 animals, and error bars represent SEM. lustatistical analysis, see Results. ( $\bullet$, unpunished; $\boldsymbol{\nabla}$, punind.)

ment of the conflict test (lever presses per session; mean \& SEM). NPY (100 pmol/side) injected into the nucleus oudatus affected neither unpunished $(116.8 \pm 16.7 \%$ a. $103.1 \pm 14.5 \%$ of baseline) nor punished (135.2 \pm H.OO vs. $128.5 \pm 15.2 \%$ of baseline) responding, showon the site specificity of the effects produced by miooinjections in to the central nucleus of the amygdala.

\section{DISCUSSION}

th the present study, ICV administration of NPY prothed both a robust increase in food intake, and a cease of punished responding in the Geller-Seifter malict test. The latter effect is similar to that seen with putypical anxiolytics, and is therefore termed "anxioFic.like." Thus, ICV administration of NPY repromed previously reported orexigenic and anxiolyticDe effects of the peptide (Clark et al. 1984; Heilig et d. 1989). In the conflict test, however, NPY also protred a smaller increase of unpunished responding, apesting that increased appetite could contribute to the apparent anxiolytic-like action of NPY in this test. Anxiolytic-like effects of ICV NPY have previously ren reported in the Vogel punished drinking test and in the elevated P-maze (Heilig et al. 1989). These two models do not rely on food reward, and are therefore bos sensitive to false-positive results due to effects on

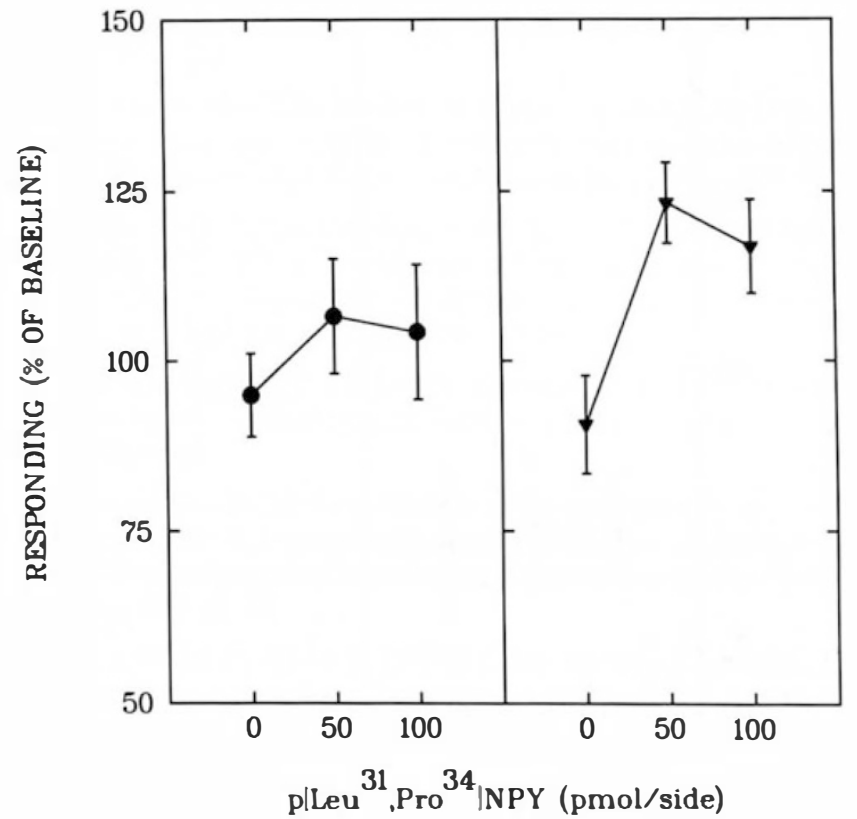

Figure 5. Increased punished, and unaffected unpunished responding after injection of the selective NPY-Y1 agonist, $\mathrm{p}\left[\mathrm{Leu}^{31}, \mathrm{Pro}^{34}\right] \mathrm{NPY}$ (50 to $100 \mathrm{pmol} /$ side) into the central nucleus of the amygdala. Responding is expressed as described in legend to Figure 1. Values are means of 8 to 10 animals, and error bars represent SEM. For statistical analysis, see Results. (•, unpunished; $\boldsymbol{\nabla}$, punished.)

food intake mechanisms. It could, however, still be argued that an increased appetitive drive can present a confound in any anxiety model, for example, by stimulating exploration. Recently, an increase of punished milk drinking was reported in mice after ICV administration of NPY (Flood and Morley 1991). Rather than anxiolytic, this effect was interpreted as indicative of "an increased motivation to eat." Thus, other means of separating the orexigenic and anxiolytic-like actions of NPY would be important. Establishing different anatomic substrates for the two effects, and demonstrating the anxiolytic-like action in the absence of increased food intake would support the hypothesis that these two functional effects are independent of each other.

A key brain structure involved in emotionality is the amygdaloid complex. In particular, the amygdaloid complex has been hypothesized to integrate autonomic responses associated with emotion (Smith and DeVito 1984), and it has been proposed that the amygdala codes the stressful affect of aversive inputs. The central nucleus of the amygdala in particular may be the point of output to areas controlling visceral responses to such information (Henke 1988). The central nucleus receives a dense network of NPY-ergic terminals (Chronwall et al. 1985), which innervate neurons projecting to the dorsal vagal complex (Gray et al. 1986). Neuropeptide $Y$-positive terminals in the central nucleus originate at least in part from cell bodies in the nucleus of the soli- 


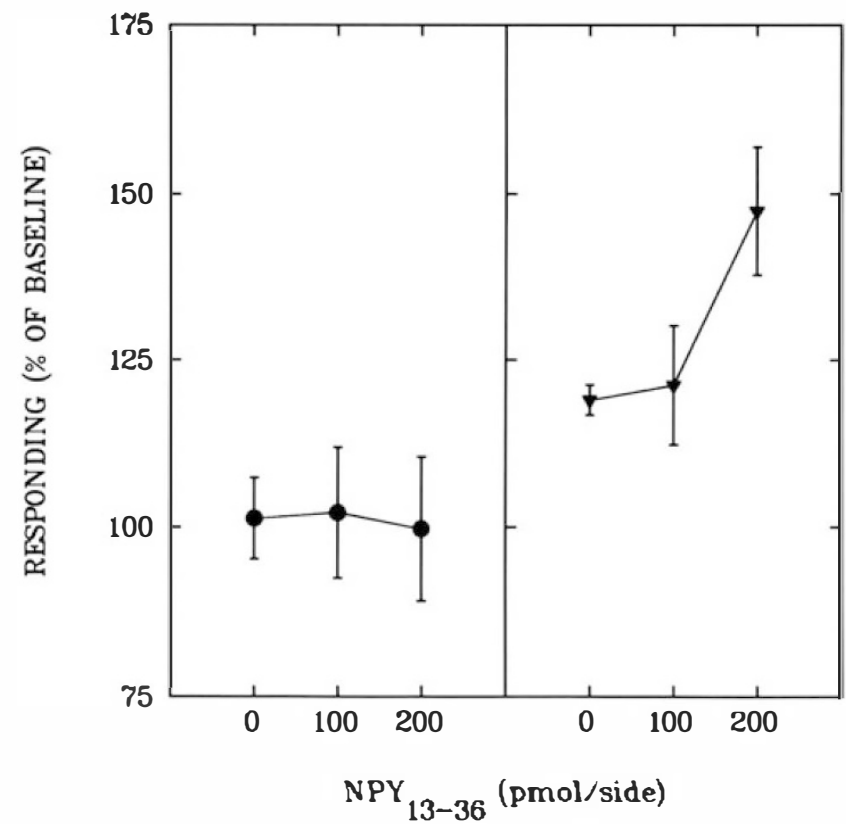

Figure 6. Unpunished and punished responding after injection of vehicle, or the selective NPY-Y2 agonist, NPY13-36 (100 to $200 \mathrm{pmol} / \mathrm{side}$ ) into the central nucleus of the amygdala. The figure illustrates the lower potency of the $Y 2$ agonist, which required a dose of $200 \mathrm{pmol} /$ side to produce a marginally significant increase of punished responding. Responding is expressed as described in legend to Figure 1. Values are means of 8 to 10 animals, and error bars represent SEM. For statistical analysis, see Results. ( $\bullet$, unpunished; $\nabla$, punished.)

tary tract. In a vast majority (80\%) of these afferents, NPY is colocalized with norepinephrine (ZardettoSmith and Gray 1990, Riche et al. 1990).

In the present study, doses of NPY as low as 50 $\mathrm{pmol} / \mathrm{side}$ injected into the amygdala produced a maximal anxiolytic-like effect in the conflict test. No effects on the nonspecific, unpunished component of the test were seen. In a separate experiment, a higher NPY dose (100 pmol/side) did not increase food intake in freefeeding rats after microinjection into the central nucleus. These observations are in agreement with studies by others. It has previously been shown that doses in this range increase food intake after injection into the hypothalamic paraventricular nucleus (Stanley and Leibovitz 1985), but are without effect on this parameter after administration into the amygdala (Stanley et al. 1985). The results of the present study support the hypothesis that the anxiolytic-like action of NPY is independent of the peptide's orexigenic effects, that the two effects are mediated by different anatomic structures, and that the central amygdaloid nucleus, at least in part, mediates the anxiolytic-like effects of NPY.

A heterogeneity of NPY receptors was initially proposed in the peripheral nervous system. It was suggested that one receptor population, termed $Y 1$, re- quired the full amino acid sequence of NPY for activation, although $Y 2$ receptors could also be activated by shorter, C-terminal fragments of NPY, such as NPY 13-36 (Wahlestedt et al. 1986). Evidence from functional studies as well as binding experiments (Heilig et al. 1988; Wahlestedt et al. 1990; Aicher et al. 1991) confirmed that a similar heterogeneity of NPY receptors was also present in the brain. In a previous study, ICV administration of NPY produced anxiolytic-like effects, and NPY13-36 was ineffective. Based on this negative evidence, it was hypothesized that anxiolyticlike actions of NPY are likely to be mediated by Y1 recep. tors (Heilig et al. 1989). Recently, a selective $Y 1$ agonist, $\mathrm{p}\left[\mathrm{Leu}^{31}, \mathrm{Pro}^{34}\right] \mathrm{NPY}$ became available (Fuhlendorff et al. 1990). In the present study, the $Y 1$ agonist was approximately equipotent with native NPY in producing are lease of punished responding, and $\mathrm{NPY}_{13-36}$ was markedly less potent. Such a hierarchy of potencies is characteristic of the recently cloned Y1 receptor (Larhammar et al. 1992). These results therefore repre sent the first positive evidence that the anxiolytic-like action of NPY is mediated by Y1 receptors. In peripheral sympathetic neuroeffector junctions, NPY coexists with norepinephrine, and potentiates postsynapticactions of the latter transmitter by activating $Y 1$ receptors (Wahlestedt et al. 1990). Since a similar colocalizz tion seems to be present in the central amygdaloid nucleus (Zardetto-Smith and Gray 1990; Riche et al. 1990), NPY could exert its anxiolytic-like effect on this structure in an analogous manner. However, NPY in the amygdala also coexists with somatostatin and gamma-aminobutyric acid in a population of intrinsic interneurons similar to those seen in the neocortex and striatum (McDonald 1989; McDonald and Pearson 1989). It remains to be established whether brain-stem afferents, local interneurons, or both are involved in mediating the anxiolytic-like effects of NPY.

It has been reported that the concentration of NPY. like immunoreactivity is decreased in the cerebrospinal fluid of depressed patients (Widerlöv et al. 1988) and in brain tissue of suicide victims (Widdowson et al. 1992), suggesting that NPY could be involved in the pathogenesis of the depressive syndrome, or parts thereof. Interestingly, in the depressed patient poptlation, a negative correlation between NPY-like immunoreactivity and anxiety scores was observed. Fur. thermore, high-performance liquid chromatography analysis of the immunoreactive material revealed that only a single peak, coeluting with native NPY was pres. ent in the controls, whereas peaks representing immunoreactive material of smaller molecular size were also detected in the patients (Heilig and Widerlöv 1990). The results of the present study suggest that activation of $Y 1$ receptors is required to produce antianxiety effects of NPY. Such an activation would require the full sequence of NPY. An increased processing and/or me- 
dism of NPY to shorter fragments could therefore inate an important endogenous antianxiety signal, dhus might contribute to anxiety symptoms seen idepression.

\section{ACKNOWLEDGMENTS}

Whalig was sponsored by a fellowship from the UCLA Profor Psychoneuroimmunology. This work was supported W.WDK Grant AM 26741 (GFK), and a VA Merit Award (10). This is manuscript 7486-NP from The Scripps Research itute. Dr. E.M. Pich is gratefully acknowledged for conluting to creating an intellectually rich environment, and $\rightarrow$ other things.

\section{REFERENCES}

He SA, Springston M, Berger SB, Reis DJ, Wahlestedt C (1991): Receptor-selective analogs demonstrate NPY/PYY meptor heterogeneity in rat brain. Neurosci Lett 130: $\$-36$

Lmwall BM, DiMaggio DA, Massari VJ, Pickel VM, Ruggero DA, O'Donohue TL (1985): The anatomy of neuropeptide-Y-containing neurons in rat brain. Neuroscience 15:1159-1181

A 4 T, Kalra PS, Crowley WR, Kalra SP(1984): Neuropepvide $Y$ and human pancreatic polypeptide stimulate feeding behavior in rats. Endocrinology 115:427-429

WfF, Morley JE (1991): Increased food intake by neuropepbide $Y$ is due to an increased motivation to eat. Peptides 12:1329-1332

"'mdorff J, Gether U, Aakerlund L, Langeland-Johansen N, Thogersen H, Melberg SG, Olsen UB, Thastrup O, Schwartz TW (1990): [Leu31,Pro34]neuropeptide Y: A perific Y1 receptor agonist. Proc Natl Acad Sci USA ஜ:182-186

$\rightarrow$ TS, O'Donohue TL, Magnuson DJ (1986): Neuropepbde $Y$ inner vation of amygdaloid and hypothalamic neuons that project to the dorsal vagal complex in rat. Pepbides 7:341-349

I. M, Wahlestedt C, Widerlöv E (1988): Neuropeptide Y NPV)-induced activity suppression in the rat: Evidence bo NPY receptor heterogeneity and for interaction with pha-adrenergic receptors. Eur J Pharmacol 157:205-213

I. M, Söderpalm B, Engel JA, Widerlöv E (1989): Centrlly administered neuropeptide Y (NPY) produces miolytic-like effects in animal anxiety models. Psydopharmacology 98:524-529

r. Widerlöv E (1990): The distribution and effects of central neuropeptide Y. Acta Psychiatr Scand 82:95-114

Ir. McLeod S, Koob GF, Britton KT (1992): Anxiolyticthe effects of neuropeptide $Y$ but not other peptides in m operant conflict test. Regul Pept 41:61-69.

WePG (1988): Recent studies of the central nucleus of the amygdala and stress ulcers. Neurosci Biobehav Rev $12: 143-150$

Jansen PAJ (1963): The inhibitory effect of fentanyl and other morphine-like analgesics on the warm water-induced tail withdrawal reflex in rats. Arzheimittel Forsch 13:502-507

Larhammar D, Blomqvist AG, Yee F, Jazin E, Yoo H, Wahlestedt $C$ (1992): Cloning and functional expression of a human neuropeptide Y/peptide YY receptor of the Y1 type. J Biol Chem 267:10935-10938

Levine AS, Morley JE (1984): Neuropeptide Y: A potent inducer of consummatory behavior in rats. Peptides 5: 1025-1029

McDonald AJ (1989): Coexistence of somatostatin with neuropeptide $Y$, but not with cholecystokinin or vasoactive intestinal peptide, in neurons of the rat amygdala. Brain Res 500:37-45

McDonald AJ, Pearson JC (1989): Coexistence of GABA and peptide immunoreactivity in non-pyramidal neurons of the basolateral amygdala. Neurosci Lett 100:53-58.

Pollard GT, Howard JV (1979): The Geller-Seifter conflict paradigm with incremental shock. Psychopharmacology 62:117-171

Riche D, De Pommery J, Menetrey D (1990): Neuropeptides and catecholamines in efferent projections of the nuclei of the solitary tract in the rat. J Comp Neurol 293:399-424

Smith OA, DeVito JL (1984): Central integration for the control of autonomic responses associated with emotion. Ann Rev Neurosci 7:43-65.

Stanley BG, Leibowitz SF (1985): Neuropeptide Y injected in the paraventricular hypothalamus: A powerful stimulant of feeding behavior. Proc Natl Acad Sci USA 82:3940-3943

Stanley BG, Chin AS, Leibowitz SF (1985): Feeding and drinking elicited by central injection of neuropeptide Y: Evidence for a hypothalamic site(s) of action. Brain Res Bull 14:521-524

Tatemoto K, Carlquist M, Mutt V (1982): Neuropeptide Y-a novel brain peptide with structural similarities to peptide $Y Y$ and pancreatic polypeptide. Nature 296:659-660

Wahlestedt C, Yanaihara N, Håkanson R (1986): Evidence for different pre- and post-junctional receptors and neuropeptide $Y$ and related peptides. Regul Pept 13:307-318

Wahlestedt C, Yanaihara N, Håkanson R, Heilig M, Shen GH, Zukowska-Grojec Z, Reis DJ (1990): Neuropeptide Y subtypes, Y1 and Y2. Ann NY Acad Sci 611:7-26

Widdowson PS, Ordway GA, Halaris AE (1992): Reduced neuropeptide $Y$ concentrations in suicide brain. J Neurochem 59:73-80

Widerlöv E, Lindström LH, Wahlestedt C, Ekman R (1988): Neuropeptide $Y$ and peptide $Y Y$ as possible cerebrospinal markers for major depression and schizophrenia, respectively. J Psychiatr Res 22:69-79

Zardetto-Smith AM, Gray TS (1990): Organization of peptidergic and catecholaminergic efferents from the nucleus of the solitary tract to the rat amygdala. Brain Res Bull 25:875-887 